\title{
The prevalence of reported asthma is independent of exposure in house dust mite-sensitized children
}

\author{
D. Vervloet*, A. Dornelas de Andrade*, L. Pascal**, A. Lanteaume*, H. Dutau*, \\ A. Armengaud**, R. Sambuc***, D. Charpin*
}

The prevalence of reported asthma is independent of exposure in house dust mite-sensitized children. D. Vervloet, A. Dornelas de Andrade, L. Pascal, A. Lanteaume, H. Dutau, A. Armengaud, R. Sambuc, D. Charpin. (C)ERS Journal Ltd 1999.

ABSTRACT: In areas with low house dust mite (HDM) allergen exposure, both mite sensitization and asthma prevalence are low. In most other areas, HDM allergen exposure is higher than the threshold for sensitization. In this setting, is HDM allergen exposure a factor which is causally related to the development of asthma in HDMsensitive individuals?

To answer this question, the cumulative prevalence of asthma was evaluated in a group of 157 schoolchildren, aged 10 and 11 yrs, who were allergic to HDM allergen, and compared it with HDM allergen exposure and atopic status, using univariate and multivariate analysis. HDM allergen levels were measured in mattress dust using an enzyme-linked immunosorbent assay (ELISA) method. Of mattress dust samples, $\mathbf{9 4 \%}$ had an HDM allergen level $>2 \mu \mathrm{g} \cdot \mathrm{g} \mathrm{dust}^{-1}$. Atopy was evaluated by means of skin prick tests using five common allergens.

Among the predictive variables studied by means of univariate analysis, only the number of positive skin tests and male sex correlated with asthma prevalence, but not HDM allergen exposure. Logistic regression analysis also demonstrated that the number of positive skin tests correlated with asthma prevalence (odds ratio $(O R)=$ 1.38, $p=0.05$ ), whereas the OR for HDM allergen exposure was 1.0.

This survey suggests that, in a geographical area with high HDM allergen exposure, asthma prevalence is not linked with HDM allergen levels. Eur Respir J 1999; 13: 983-987.

\begin{abstract}
*Unité Propu de l'Enseignement Supérieur Jeune Equipe $\mathrm{N}^{\circ}$ 2050, Hôpital Sainte Marguerite, **Cellule Inter-Régionale d'Epidémiologie d'Intervention, Direction Régionale des Affaires Sanitaires et Sociales, and $* * *$ Laboratoire de Santé Publique, Faculté de Médecine, Marseille, France.
\end{abstract}

Correspondence: D. Charpin, Service de Pneumologie-Allergologie, Hôpital Nord, Chernin des Bourrely, 13915 Marseille Cedex 20, France, Fax: 33491090994

\section{Keywords: Allergy \\ asthma \\ environment \\ house dust mites}

Received: August 271996

Accepted after revision April 41998

Supported by the Ministere de la Santé, des Affaires Sociales et de la Solidarité, Ministère de l'Environnement, ADEME agency, Réseau National de Santé Publique, Conseil Général des Bouches du Rhône, town councils and major local industries.

It has been stated that house dust mite (HDM) allergen exposure is the dominant environmental cause of asthma fulfilling Bradford-Hill's criteria for causality [1, 2]. A few studies have demonstrated a lower prevalence of asthma in areas with low HDM allergen levels [2-4] and avoidance has been shown, in some studies [5], to be useful as a primary prevention method. It is noteworthy that these areas have very particular climatic conditions (cold and/or dry), which are responsible for the very low level of mite infestation. Thus a low prevalence of asthma is associated with a low prevalence of HDM allergy. In contrast, in most other parts of the developed world, HDM allergen levels are quite high [6], leading to a high percentage of HDM allergy in the general population $[7,8]$. In this setting, it is questioned whether HDM exposure could also be a factor which is causally related to the subsequent development of asthma in mite-sensitive individuals, or whether asthma is mainly linked to the atopic status. To answer this question, the cumulative prevalence of asthma was evaluated with respect to mite allergen levels and atopic status by questioning the parents of a group of schoolchildren allergic to mites.

\begin{abstract}
Methods
Material

The study group included a group of 157 children, allergic to HDMs, who provided a mattress dust sample.
\end{abstract}

\section{Protocol}

These children were part of a cross-sectional epidemiological survey, performed from January to April 1993 in the Fos-L'Etang de Berre area, which is an industrial area located west of Marseilles, France. It included all the 4th and 5 th grade children (mean \pm SD age: $10.7 \pm 0.7$ yrs) from the state schools of the towns in this area, which has a mild temperate climate. The mean $( \pm \mathrm{SD})$ annual temperature between 1985 and 1993 was $14.9 \pm 0.4^{\circ} \mathrm{C}$, and the mean $( \pm \mathrm{SD})$ annual relative humidity $(\mathrm{RH})$ was $73.0 \pm 5.0 \%$.

The protocol included a questionnaire, which was filled in by the parents or guardians, skin tests to common allergens and measurement of mite allergens in house dust 
collected from the children's mattresses. A bronchial challenge test to measure nonspecific bronchial reactivity, was not performed. The questionnaire, derived from the 1978 American Thoracic Society Questionnaire for children (ATS-DLD-78-C) [9], asked about socio-economic status (low, medium or high), medical history, passive smoking, divided into 3 categories (none, $<10$ cigarettes smoked at home when child present or $>10$ cigarettes daily), and asthma. Asthma was defined by a positive answer to the question: "Has your child ever had asthma?". Information on implementation of mite-avoidance procedures was not collected, apart from the possession of anti-allergic mattress covers, which were not used on any of the children's beds. Skin prick tests were performed using a multitest

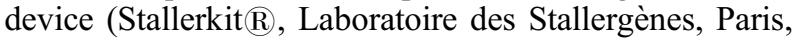
France). This device has been shown to be valid compared to standard skin prick tests [10]. It is also more suitable for epidemiological studies because it allows serial examinations in a shorter time and induces less pain. Allergens put onto the device were chosen according to the authors' previous study [11], performed in 1,000 outpatients visiting their allergy clinic. This study demonstrated that, in the authors' region, the most relevant inhaled allergens are as follows: Dermatophagoides pteronyssinus, cat dander, grass and cypress pollen and Alternaria. In addition to these five allergens, Stallerkit $(\mathrm{R})$ includes one negative (Coca solution) and two positive controls ( $9 \%$ codeine phosphate), located at opposite corners of the device. The allergenic potency of the extracts is expressed in terms of reactivity units. $\mathrm{mL}^{-1}$. A 100-reactivity index solution of a given allergen induces a 7-mm diameter weal, in a group of patients sensitized to this allergen. Tests were performed on the volar surface of the forearm, by pressing the device gently onto the skin. The results were determined 20 min later, using a ruler to measure the mean diameter of the weal. A test was considered positive if the weal diameter was at least half that induced by codeine phosphate, and larger than the weal induced by the control solution. The mean ( \pm SD) weal diameter induced by the codeine phosphate test was $4.2 \pm 1.5 \mathrm{~mm}$. Thus, a test was considered positive if its mean diameter was $\geq 2.1 \mathrm{~mm}$. The size of the weal was also measured for each positive allergen. All of the children included in this study had a positive skin test to HDM allergen.

The children were asked to bring a sample of mattress dust to school with them. Dust collection was performed by their parents, who were given a form explaining the sampling procedure: from the whole of the upper mattress surface, sampling time of $2 \mathrm{~min} \cdot \mathrm{m}^{-2}$, and according to the international recommendations [12]. Parents vacuumed into a new bag, and brought the dust sample to the school. Disposable paper bags were collected and stored at $4{ }^{\circ} \mathrm{C}$, until processed. The fine dust was collected and weighed. Samples containing $<100 \mathrm{mg}$ fine dust were discarded. The mite allergen content was assayed by means of an enzyme-linked immunosorbent assay (ELISA) using monoclonal antibodies [13]. The assay was performed using a double-control method. The antigen concentration used in the statistical analysis was the arithmetic mean of the values in the linear section of the standard curve. The results were expressed as $\mu \mathrm{g}$ group I mite antigens.g house dust $^{-1}$.

\section{Statistical analysis}

The cumulative prevalence of asthma was compared with HDM allergen levels, and with atopic status, evaluated using the number of positive tests, via the simple Chisquared test. The relationship between exposure to HDM allergens and the cumulative prevalence of asthma was evaluated by Chi-squared tests with two degrees of freedom. In this part of the analysis, the mite allergen exposure was divided into three levels $(<2,2-10$ and $>10 \mu \mathrm{g} \cdot \mathrm{g}$ dust $^{-1}$ ) because 2 and $10 \mu \mathrm{g}$ have been suggested as the thresholds for sensitization to mite allergens and for the triggering of symptoms in sensitized patients, respectively [12]. Finally, logistic regression analysis was performed using the cumulative prevalence of asthma as a dependent variable, and log of HDM allergen levels, number of positive tests and sex as independent variables. Mean weal diameter had, as a variable, a high colinearity with the number of positive skin tests. For the sake of comparison with the international literature, only the latter variable was kept in the analysis. Socio-economic status and passive smoking were not included in this analysis because they were not found to correlate with the cumulative asthma prevalence.

\section{Logistics}

The children's parents had to fill in the questionnaires. They were also asked for written informed consent for performing skin testing on their children. The study received approval from the Ethical Committee. Skin testing was performed at school. Results of the skin tests were immediately given to the parents and to the family doctor. Collection of mattress dust was performed by the parents, who brought the dust sample to school.

\section{Results}

The study group included 167 HDM-allergic children, whose parents provided a sample of mattress dust. However, 10 samples did not contain enough dust. Thus, 157 children were included in this study (table 1). It was noteworthy that the prevalence of asthma was similar in the children whose parents granted permission for skin testing and in those whose parents refused permission (9.0 and $10.4 \%$, respectively). Similarly, the prevalence of asthma was similar in HDM-allergic children who provided house dust and in those who did not (23.8 and $21.8 \%$, respectively).

\section{Variables potentially predictive of asthma apart from house dust mite-exposure}

Table 2 displays the cumulative prevalence of asthma, according to the categorical variables tested. Among the variables evaluated, none correlated with the prevalence

Table 1. - Characteristics of the study group

\begin{tabular}{lccc}
\hline & Males & Females & p-value \\
\hline Subjects n (\%) & $98(62)$ & $59(38)$ & \\
Mean ( \pm SD) age yrs & $10.7 \pm 0.6$ & $10.7 \pm 0.8$ & NS \\
Asthma prevalence \% & $31.5 \pm 4.7$ & $12.1 \pm 4.2$ & 0.007 \\
\hline
\end{tabular}


Table 2. - Cumulative prevalence of asthma according to qualitative variables under study

\begin{tabular}{lccc}
\hline & & $\begin{array}{c}\text { Subjects* } \\
\mathrm{n}\end{array}$ & $\begin{array}{c}\text { Asthma } \\
\text { prevalence \% }\end{array}$ \\
\hline Socio-economic & Low & 38 & 27.5 \\
status & Medium & 52 & 37.7 \\
& High & 48 & 34.8 \\
Passive smoking ${ }^{+}$ & Absent & 71 & 22.5 \\
& Moderate & 43 & 27.9 \\
No. positive & High & 19 & 36.8 \\
skin tests & 1 or 2 & 99 & 17.1 \\
Group I mite & $\geq 3$ & 41 & $43.9 * *$ \\
allergen $\mu \mathrm{g} \cdot \mathrm{g}^{-1}$ & $2-10 \mu \mathrm{g}$ & 9 & 33.3 \\
& $>10 \mu \mathrm{g}$ & 100 & 19.4 \\
& & 31 & 26.0 \\
\hline
\end{tabular}

*: Some values missing. ${ }^{+}$: absent: none; moderate: $<10$ cigarettes smoked at home when child present; high: $>10$ cigarettes daily. ${ }^{* *}: \mathrm{p}=0.01$.

of asthma apart from the number of positive skin tests $(p=0.004)$. The mean $( \pm S D)$ weal diameter of the skin reactions was $1.39 \pm 0.9 \mathrm{~mm}$ in the nonasthmatic children and $1.9 \pm 1.3 \mathrm{~mm}$ in the asthmatic children $(\mathrm{p}=0.01)$. The mean $( \pm \mathrm{SD})$ weal diameters using HDM allergen were $1.64 \pm 2.06 \mathrm{~mm}$ and $2.76 \pm 2.43 \mathrm{~mm}$, respectively.

\section{The influence of house dust mite-exposure}

The group I allergen level varied from 0.1 (threshold) to $185.1 \mu \mathrm{g} \cdot \mathrm{g}$ dust $^{-1}$, with a geometric mean of 14.3 (median 19 ). Of note was that $94 \%$ of samples had a group I allergen level of $>2 \mu \mathrm{g}$ (fig. 1). Table 2 displays the cumulative prevalence of asthma according to HDM allergen levels. No association was found $(p=0.63)$ between the two variables. Among the children with a history of asthma, 91.4\% had an HDM allergen level $>2 \mu \mathrm{g}$. This exposure was $94.6 \%$ in the nonasthmatic children. Linear logistic regression analysis using the cumulative prevalence of asthma as the dependent variable once again demonstrated that HDM exposure did not correlate with the cumulative prevalence of asthma (table 3 ). The odds ratio $(\mathrm{OR})$ for the prevalence of asthma with respect to the

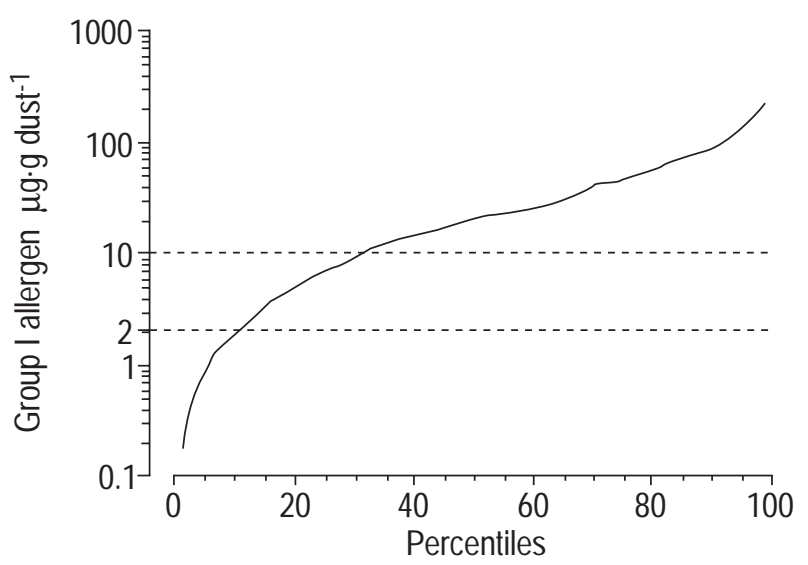

Fig. 1. - Relative cumulative frequency distribution of group I allergen concentrations in mattresses. number of positive skin tests ( 1 or 2 positive tests compared with $\geq 3$ positive tests) was $1.38(\mathrm{p}=0.05)$, whereas the OR with respect to HDM allergen levels was $1.0(\mathrm{p}=$ $0.44)$.

\section{Discussion}

This cross-sectional epidemiological study strongly suggests that atopic status is the major risk factor for the occurrence of asthma, as opposed to mite allergen exposure. In the present data, an increased risk of asthma, according to the number of positive skin tests found, was marginally significant. This is because the study group only included children allergic to mites, and because mite allergens are known, amongst all common aeroallergens, as those which are predictive for the occurrence of asthma [14]. In other surveys including children both sensitized and nonsensitized to mites, this association is stronger [14]. In this latter study, the percentage of asthma symptoms increased, in a dose-dependent manner, from $34.3 \%$ in nonatopic children to $90 \%$ in children sensitized to seven or more allergens.

The new finding emerging from this survey is that mite allergen exposure was not a risk factor for the occurrence of asthma among children already sensitized to mite allergens. Dust sampling was performed by the parents. The percentage of samples containing $<100 \mathrm{mg}$ dust was only $17 \%$, indicating that sampling was performed correctly in most cases. In this cross-sectional study, cumulative asthma was compared with a single mite allergen measurement performed at the time of the study. However, mattresses can be considered as allergenic reservoirs, thus providing an index reflecting cumulative exposure. Few studies show that mite allergen exposure is a risk factor for the occurrence of asthma. The study of SPORIK et al. [15] did not find any difference in mite allergen exposure levels among the subgroups "no history of wheezing", "history of wheezing", "active wheezing and bronchial hyperreactivity" and "receiving medication". There was no relationship between exposure to mite allergens at the age of $1 \mathrm{yr}$ and current symptoms. Such a relationship was demonstrated only in atopic children, but it could be argued [16] that the children who developed asthma were also those who were most atopic. In addition to the study of SPORIK et al. [15], mentioned above, another larger prospective study was conducted in schoolchildren aged 7-10 yrs [17]. It concluded that the occurrence of asthma in mitesensitized children was not dependent upon mite exposure. Another important study, performed in a large group of Australian schoolchildren [2], convincingly demonstrated a close correlation between risk of current asthma in HDM-sensitized children and HDM allergen levels. However, in this latter study, HDM allergen levels were very high in some communities and very low in others. The other available evidence for a causal relationship between mite exposure and the occurrence of asthma comes from studies performed at high altitude. A significantly lower prevalence of asthma could be demonstrated in adults [18], with a similar trend exhibited in children [3]. In populations living at high altitude, exposure to mite allergens is approximately 50-times less than that at sea level [3]. Such low exposure levels lead to a low prevalence of mite allergen-sensitization $[19,20]$, which 
Table 3. - Logistic regression analysis relating cumulative asthma prevalence to predicting variable (group I allergen level is omitted because it is not predictive)

\begin{tabular}{lcccccrr}
\hline Variable & $\mathrm{b}$ & SEM & Wald & df & p-value & r & OR (95\% CI) \\
\hline No. positive skin tests & 0.4779 & 0.1826 & 6.8474 & 1 & 0.0089 & 0.1859 & $1.62(1.13-2.31)$ \\
Sex (male:female) & 1.3350 & 0.4916 & 7.3735 & 1 & 0.0066 & 0.1958 & $3.80(1.45-9.96)$ \\
\hline
\end{tabular}

df: degrees of freedom; OR: odds ratio; CI: confidence interval.

is in turn responsible for a lower prevalence of atopic diseases. Such differences in mite allergen-exposure are unlikely to be commonly found within the same geographical area $[21,22]$. Therefore mite-sensitization occurs in all genetically predisposed individuals, irrespective of the magnitude of the exposure. This is due to the ubiquitous nature of these antigens. In like manner, the presence of pets inside the house does not influence the development of atopy in children [23, 24] because these allergens can be detected at significant levels even in houses without pets. Recent experimental and epidemiological investigations strongly suggest that the threshold for allergic sensitization to HDMs might be well below 2 $\mu \mathrm{g} \cdot \mathrm{g}$ dust $^{-1}$ [25]. Ihre and ZetTerstrom [26] performed bronchial allergen challenges once a day over 7 consecutive working days in a group of asthmatic subjects. No immediate symptoms were recorded. Interestingly, nonspecific bronchial hyperreactivity, as measured by bronchial histamine provocation tests, increased significantly after the allergen challenge period in comparison with that found beforehand. The specific challenge consisted of inhalation of $1 \mathrm{ng}$ of a major allergen for a few minutes per day. PRICE et al. [27] suggested a lower threshold (0.5 $\mu \mathrm{g} \cdot \mathrm{g} \mathrm{dust}^{-1}$ ) for sensitization, based on the results of a retrospective study in infants. WARNER et al. [28] compared current HDM allergen-exposure at home, in 124 children with perennial asthma living in Sweden, with skin reactivity and specific serum immunoglobulin $\mathrm{E}$ directed against mites. There were 45 houses with HDM allergen concentrations of $0.016-2 \mu \mathrm{g} \cdot \mathrm{g}$ dust $^{-1}$. Fifteen of the children living there were sensitized to HDMs. Statistical analysis revealed that the HDM-exposure level was associated with sensitivity, even at the low range of allergen concentrations found. There was also a strong correlation between HDM-exposure and serum mite-specific immunoglobulin E levels, even for HDM levels well below $2 \mu \mathrm{g} \cdot \mathrm{g}$ dust $^{-1}$.

In conclusion, the risk of the occurrence of asthma in sensitized individuals depends on the degree of atopy (number of positive skin tests). Mite allergen exposure was not predictive of the occurrence of asthma. The authors' hypothesis is that house dust mite-exposure is so ubiquitous in the area studied that virtually all genetically-predisposed individuals become sensitized to mites, whatever the HDM allergen level, which were in most cases far above the threshold for sensitization.

Acknowledgements. The authors would like to thank the staff of the schools (medical director: F. Brisse) who helped in organizing data collection, and the children and their families who participated in the study.

\section{References}

1. Platts-Mills TAE, Sporik R, Chapman MD, Heymann PW. The role of indoor allergens in asthma. Allergy 1995; 50 (Suppl. 22): 5-12.

2. Peat JK, Tovey E, Toelle BG, et al. House dust mite allergens. A major risk factor for childhood asthma in Australia. Am J Respir Crit Care Med 1996; 153: 141146.

3. Charpin D, Birnbaum J, Haddi E, et al. Altitude and allergy to house-dust mites. A paradigm of the influence of environmental exposure on allergic sensitization. $\mathrm{Am}$ Rev Respir Dis 1991; 143: 983-986.

4. Herxeimer H, Schaefer O. Asthma in Canadian Eskimos. N Engl J Med 1975; 291: 1419 (letter).

5. Arshad SH, Matthews S, Gant C, Hide DW. Effect of allergen avoidance on development of allergic disorder in infancy. Lancet 1992; 339: 1493-1497.

6. Colloff MJ. The global distribution of major species of dust mites. In: Van Moerbeke V. Proceedings of the 3rd International Workshop on Indoor Allergens and Asthma, Cuenca, Spain, June 30-July 2, 1995. Braine 1'Alleud, UCB Institute of Allergy, 1997; p. 11.

7. Kuehr J, Frischer J, Meinert R, et al. Mite exposure is a risk factor for the incidence of specific sensitization. $J$ Allergy Clin Immunol 1994; 94: 49-52.

8. Kuehr J, Karmaus W, Forster J, et al. Sensitization to four common inhalant allergens within 302 nuclear families. Clin Exp Allergy 1993; 23: 600-605.

9. Ferris BG. Recommended respiratory disease questionnaires for use in adults and children epidemiological research: epidemiology standardization project. Am Rev Respir Dis 1978; 118: 1-53.

10. Berbig B, Von Mutius E, Nicolai T. Untersuchungen zu einem multiallergenen Testemplen im vergleich zum Prick-Test. Allergologie 1991; 14: 51-57.

11. Birnbaum J, Rovira AC, Lanteaume A, Vervloet D, Charpin D. Relationships between type of allergic sensitization and symptoms. J Allergy Clin Immunol 1995; 95: A265.

12. Platts-Mills TAE, de Weck AL. Dust mite allergens and asthma - a worldwide problem. J Allergy Clin Immunol 1989; 83: 416-427.

13. Luczynska CM, Arruda LK, Platts-Mills TAE, Miller JD, Lopez M, Chapman MD. A two-site monoclonal antibody ELISA for the quantitation of the major Dermatophagoides spp. allergens, Der p I and Der f I. J Immunol Methods 1989; 118: 227-235.

14. Sears MR, Herbison GP, Goldaway MD, Hewitt CJ, Flannery EM, Silva PA. The relative risks of sensitivy to grass pollen, house dust mite and cat dander in the development of childhood asthma. Clin Exp Allergy 1989; 19: 419-424.

15. Sporik R, Holgate ST, Platts-Mills TAE, Cogswell JJ. Exposure to house-dust mite allergen (Der $\mathrm{p} \mathrm{I}$ ) and the development of asthma in childhood. A prospective study. $N$ Engl J Med 1990; 323: 502-507. 
16. Harding CV. House-dust mite allergen and asthma. $N$ Engl J Med 1991; 324: 337-338.(letter).

17. Kuehr J, Friescher T, Meinert R, et al. Sensitization to mite allergens is a risk factor for early and late onset of asthma and for persistence of asthmatic symptoms in children. J Allergy Clin Immunol 1995; 95: 655-662.

18. Charpin D, Kleisbauer JP, Lanteaume A, et al. Asthma and allergy to house dust mites in population living in high altitudes. Chest 1988; 93: 758-761.

19. Lau S, Falhenhorst G, Weber A, et al. High mite-allergen exposure increases the risk of sensitization in atopic children and young adults. J Allergy Clin Immunol 1989; 84: 718-725.

20. Wickmann M, Nordvall SL, Pershagen G, Sundell J, Schwartz B. House dust mite sensitization in children and residential characteristics in a temperate region. $J$ Allergy Clin Immunol 1991; 88: 89-95.

21. Wickman M. Prevention and non pharmacologic treatment of mite allergy. Allergy 1997; 52: 369-373.

22. Marks GB, Tovey ER, Toelle BG, Wachinger S, Peat JK, Woolcock AJ. Mite allergen (Der pI) concentration in houses and its relation to the presence and severity of as- thma in a population of Sydney schoolchildren. $J$ Allergy Clin Immunol 1995; 96: 441-448.

23. Arshad SH, Stevens M, Hide DW. The effect of genetic and environmental factors on the prevalence of allergic disorders at the age of two years. Clin Exp Allergy 1993; 23: 504-511.

24. Horwood LJ, Fergusson DM, Shannon FT. Social and familiar factors in the development of early childhood asthma. Pediatrics 1985; 75: 859-868.

25. Dreborg S. Very low allergen levels cause chronic bronchial hyperreactivity - a hypothesis. Allergy Clin Immunol News 1993; 5: 59-60.

26. Ihre E, Zetterstrom O. Increase in non-specific bronchial responsiveness after repeated inhalation of low doses of allergen. Clin Exp Allergy 1993; 23: 298-305.

27. Price JA, Pollock I, Little S, Longbottom JL, Warner JO. Measurement of airborne mite antigen in homes of asthmatic children. Lancet 1990; 338: 895-897.

28. Warner AM, Bjorksten B, Munir AKM, Moller C, Kjellman NIM. Childhood asthma and exposure to indoor allergens: low mite levels are associated with low mite sensitivy. Pediatr Allergy Immunol 1996; 7: 61-67. 